
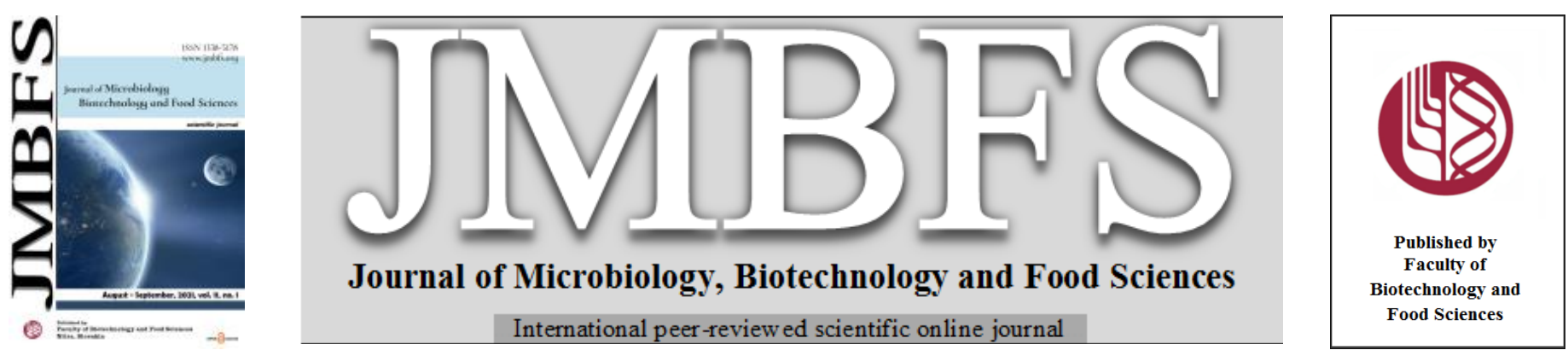

\title{
INFLUENCE OF QUERCETIN AND DIHYDROQUERCETIN ON SOME FUNCTIONAL PARAMETERS OF RAT LIVER MITOCHONDRIA
}

\author{
${ }^{I}$ Ulugbek G. Gayibov*, ${ }^{1}$ Sabina N. Gayibova, ${ }^{3}$ Ma'murjon K. Pozilov, ${ }^{2}$ Feruza Sh. Tuxtaeva, ${ }^{2}$ Umida R. Yusupova, ${ }^{2}$ Gulchehra M.-K. \\ Djabbarova, ${ }^{2}$ Zulayho A. Mamatova, ${ }^{3}$ Nurali A. Ergashev, ${ }^{1}$ Takhir F. Aripov
}

Address(es): Ulugbek G. Gayibov,

${ }^{1}$ Institute of Bioorganic Chemistry named after acad. A.S. Sadykov, Academy of Sciences of Uzbekistan, 83, Mirzo Ulugbek street, 100125, Tashkent, Uzbekistan. ${ }^{2}$ National University of Uzbekistan named after M.Ulugbek, Universitet street, Tashkent, Uzbekistan.

${ }^{3}$ Institute of Biophysics and Biochemistry under National University of Uzbekistan, Universitet street, Tashkent, Uzbekistan.

*Corresponding author: gayibov.ulugbek@gmail.com

https://doi.org/10.15414/jmbfs.2924

\section{ARTICLE INFO}

Received 9. 4. 2020

Revised 18. 2. 2021

Accepted 24. 2. 2021

Published 1. 8. 2021

Regular article open 2 access

\section{ABSTRACT}

Flavonoids are proved to be prominent plant-derived compounds generally found in fruit- and vegetable- rich diets with free radicals quenching ability. Quercetin, a member of flavonoids subclass - flavonols, has gained major attention due to its overwhelming potential. Quercetin was demonstrated to preserve diverse degenerative diseases by inhibiting lipid peroxidation. In the present paper, we deal with two polyphenolic compounds' - quercetin and dihydroquercetin - influence on functional parameters of mitochondria. Thus, the fore mentioned flavonols showed the mitochondrial permeability transition pore (mPTP) inhibition and ATP-sensitive potassium channel activation capacities as well as strong antioxidant/antiradical activity. Improving functional parameters of mitochondria by both quercetin and dihydroquercetin formed a basic idea of the hypothesis that the studied flavonols may provide antihypoxic defense.

Keywords: flavonoids, antioxidant activity, antihypoxic agents, mPTP, mitoKATP

\section{INTRODUCTION}

Mitochondria play a major role in the apoptosis and necrosis regulation (Dave, Byfield, et al., 2008; Vladimirov, 2002; Shimizu, Tsujimoto, 2007). The parameters like mPTP, oxidation phosphorylation, antioxidant defense systems, and others regulate the functionality of mitochondria (Pozhilova, Levchenkova, et al., 2014). The swollen mitochondria initiates opening of $\mathrm{mPTP}$ that leads to the rupture of the outer mitochondria membrane as well as intermembrane components leakage into the cytosol provoking the process of cell apoptosis. The $\mathrm{Ca}^{2+}$ ions accumulation in the matrix of the mitochondria is also a direct regulatory mechanism for opening the mitochondrial pore, a key link in the launch of the cell apoptosis program (Dave, Byfield et.al, 2008; Tsujimoto, Shimizu, 2007). The formation and opening of mPTP is not the only mechanism for the leakage of mitochondria intermembrane components into the cytosol. However, the search for medicinal substances, the target of which will be the mitochondrial mega pore, can become a promising direction in the correction of many pathological conditions (Novikov, Levchenkova, 2013). Also, recently, interest in the study of the mitochondrial ATP-sensitive potassium channel (mitoKATP channel) has increased, since it has been established that its activation plays a key role in protecting organs and tissues from the effects of ischemia/reperfusion (Akao, Ohler et .al, 2001) and in addition to its important role, the mitoKATP channel plays a huge role in adapting the body to various stress factors (Danilenko, Lokrovsky et al., 2010; Hund, Mohler, 2011).

It is known that the opening of the mitoKATP channel leads to depolarization of the membrane potential of mitochondria and causes the reversible oxidation of flavoproteins of the respiratory chain, thereby increasing the production of reactive oxygen species (ROS) in mitochondria (Samavati, Monick et.al, 2002). But in a review, Pozhilova et al. show that the natural metabolic activators of the mitoKATP channel, uridine and its nucleotides in micromolar concentrations, significantly reduce the area of myocardial infarction, normalize the level of ATP, creatine phosphate and antioxidant defense systems, reducing the formation of ROS, and normalize the heart rate by rat myocardial infarction models (Pozhilova, Levchenkova et al., 2014). It is also mentioned that the opening of the mitoKATP channel leads to a decrease in ROS in tissue cells, thereby regulating it (Ferranti, da Silva et al., 2003; Facundo, de Paula et al., 2007; Fornazari, de Paula et.al, 2008) Thus, the activation of the potassium cycle upon adaptation to the stress factor and the subsequent decrease in ROS formation can explain the known protective role of the mitoKATP channel in ischemia/reperfusion (Garlid and Halestrap, 2012; Meng, Ma et.al, 2016).

Activation of lipid peroxidation (LPO) is often one of the triggers of many diseases and is also an aggravating factor in many pathological conditions (Mylonas, Kouretas, 1999; Lobo, Patil et.al, 2010; Chesnokova, Morrison et al., 2009). Moreover, the use of antioxidants in the treatment of various pathological conditions of the body slows down the course of pathological conditions caused by an excess of free radicals, since antioxidants can prevent the activation of induced free radical reactions (Brewer, 2011). Thus, it can be concluded from the above material that compounds with antioxidant activity can be considered as promising universal remedies promoting the prevention and treatment of a oxidative stress caused disorders.

Given the above, studies regarding the molecular and cellular mechanisms of plant compounds actions are currently considered relevant to detect potential pharmacological agents with effect on the organism. One of the potential pharmacological agents is polyphenol compounds of plants. Polyphenolic compounds have a very wide spectrum of action on biological objects, exhibiting antioxidant, hepatoprotective, antihypoxic, membrane-tropic and many other effects (Asrarov, Komilov et al., 2015; Rustamova, Irgasheva, et al., 2005; Tsybulsky, Popov et al., 2011). The manifested physiological responds of cells exposed to polyphenols are observed due to polyphenols' ability to alter the mitochondrial membrane permeability with respect to particular ions that is crucial in preventing of different pathological conditions in an organism. It's been widely accepted that quercetin, typical component of onions, buckwheat and citrus fruit and utilized in traditional medicine as preventive agent against variety of diseases, such as cancer (Zhang et al. 2011; Jovanovic, 1999; Mullen, 2008), cardiovascular and nervous disorders (Shankar, 2007; Labinskyy, 2006), obesity (Yang et al. 2008), and chronic inflammation (Teixeira S., 2002; Garcha-Mediavilla V., 2007) possesses its therapeutic effect through immense antioxidant activity. Although the underlying mechanisms of biological action are largely under debate, the quercetin structure suggests multi-functional and mitochondria-mediated mechanism (Karbarz M, 2008).

Being a significant member of the flavonol subclass, quercetin, has attracted considerable attention. Moreover, quercetin and its glucosylated forms contribute to $60-75 \%$ of flavonoid intake (Bouktaib et al. 2002). 
Oxidized low-density lipoproteins (LDL), that are hallmarks of certain diseases, such as cancer, atherosclerosis, and chronic inflammation (Hollman and Katan 1997; Murota and Terao 2003), were shown to be strongly inhibited by quercetin both by free radicals scavenging mechanism and chelating transition metal ions.

Thus, in this work, we studied the comparative mechanism of effect of two flavonoids (the quercetin and its derivative dihydroquercetin) on some functional parameters of mitochondria, such as $\mathrm{mPTP}$, mitoKATP channel, and LPO of rat liver mitochondria.<smiles>O=c1c(O)c(-c2ccc(O)c(O)c2)oc2cc(O)cc(O)c12</smiles><smiles>O=C1c2c(O)cc(O)cc2OC(c2ccc(O)c(O)c2)C1O</smiles>

A

B

Figure 1 Chemical structures of quercetin (A) and dihydroquercetin (B)

\section{MATERIALS AND METHODS}

\section{Mitochondria isolation}

Mitochondria isolation protocol was followed as described by (Schneider, Hageboom, 1951) from rat liver tissue homogante (white outbred rats, both sexes, 180-200 g). In brief, rat liver tissue was homogenized on ice, medium A contained sucrose $(250 \mathrm{mM})$, EDTA $(0.5 \mathrm{mM})$, Tris- $\mathrm{HCl}$ buffer $(10 \mathrm{mM})$ adjusted to $\mathrm{pH} 7.4$, centrifuged at $1500 \mathrm{~g}$ for $7 \mathrm{~min}\left(-2\right.$ to $\left.-4{ }^{\circ} \mathrm{C}\right)$. After centrigugation supernatant was collected and mitochondria was precipitated at $6000 \mathrm{~g}$ for $15 \mathrm{~min}\left(-2\right.$ to $\left.-4^{\circ} \mathrm{C}\right)$, resuspended in medium A lacking EDTA, and stored on ice until needed. The mitochondrial protein amount was measured by the Lowry protein assay with minor modifications (Peterson, 1977). All experiments were performed at room temperature, on colorimeter Granat, Russia, 1991.

\section{Mitochondria swelling assay}

The opening of mPTP was observed through mitochondrial swelling by recording the spatial light scatter intensity at $540 \mathrm{~nm}$ in the presence of $10 \mathrm{mM} \mathrm{Ca}{ }^{2+}$ as a control. $1 \mathrm{ml}$ of mitochondrial solution contained 0.3-0.4 mg protein. The buffer contained sucrose $(200 \mathrm{mM})$, EGTA $(20 \mu \mathrm{M})$, succinate $(5 \mathrm{mM})$, rotenone $(2$ $\mu \mathrm{M})$, oligomycin $(1 \mu \mathrm{g} / \mathrm{ml})$, Tris $(20 \mathrm{mM})$, HEPES $(20 \mathrm{mM}), \mathrm{KH}_{2} \mathrm{PO}_{4}(1 \mathrm{mM})$ adjusted to $\mathrm{pH} 7.2$ (He, Lemasters, 2003). Polyphenols were added at the 1-100 $\mu \mathrm{M}$ concentration range

\section{mitoK $_{\mathrm{ATP}}$ current recording}

mitoKATP channel current recording was monitored at $540 \mathrm{~nm}$ in external solution contained $\mathrm{KCl}(125 \mathrm{mM})$, Hepes $(10 \mathrm{mM})$, succinate $(5 \mathrm{mM}), \mathrm{MgCl}_{2}(1$ $\mathrm{mM}), \mathrm{K}_{2} \mathrm{HPO}_{4}(2.5 \mathrm{mM}), \mathrm{KH}_{2} \mathrm{PO}_{4}(2.5 \mathrm{mM})$, rotenone $(0.005 \mathrm{mM})$, oligomycin (0.001 mM) (Vadzyuk, Kosterin, 2008). Polyphenols were added at the 1-50 $\mu \mathrm{M}$ concentration range. $10 \mathrm{mM}$ of ATP was accepted as control.

\section{Lipid peroxidation assay}

Lipid peroxidation (LPO) was initiated by $\mathrm{Fe}^{2+} /$ ascorbate system in mitochondria suspension, external medium contained: $\mathrm{KCl}(125 \mathrm{mM})$, Tris- $\mathrm{HCl}(10 \mathrm{mM}), \mathrm{pH}$ adjusted to 7.4, according to (Schneider et al., 1948). $1 \mathrm{ml}$ of mitochondria solution contained $0.5 \mathrm{mg}$ protein. $10 \mu \mathrm{M} \mathrm{FeSO}_{4}$ together with $600 \mu \mathrm{M}$ ascorbate were added to medium to generate process of mitochondrial swelling. The experiments were carried out $24-26^{\circ} \mathrm{C}$.

\section{DPPH assay}

DPPH kinetics was carried out as described elsewhere (Gayibova, 2019) Briefly, the kinetic results regarding DPPH $(0.1 \mathrm{mM})$ decolorization in the presence of polyphenols (up to $10 \mu \mathrm{M}$ ) was recorded on SF-46 (LOMO, Russia 1996). The spectroscopic data was fixed every $15 \mathrm{sec}$ until the reaction reached steady state.

\section{Conductometry}

The conductivity of the solutions was measured using a Sartorius Professiona meter PP-20 conductometer (USA) at a temperature of $25^{\circ} \mathrm{C}$, at a constant salt concentration and a variable concentration of polyphenols. During the experiment, a weighed portion of polyphenols was dissolved in $20 \mathrm{ml}$ of water, and then the conductivity was measured by successively diluting a solution of divalent metal salt (initial concentration of $10^{-3} \mathrm{M}$ ) with certain volumes of the

initial solution of the substance $(0.01 \mathrm{M})$ (Andreev, 1971).

\section{Chemical reagent}

EDTA, EGTA and cyclosporine A were purchased from "Sandoz", Switzerland, rotenone and tris- $\mathrm{HCl}$ were from "Serva", Germany, $\mathrm{DPPH}$ and $\mathrm{CaCl}_{2}$ were from "Sigma", USA. Other reagents were purchased from the local companies with grade marked as "chemically pure".

\section{Data analysis}

A statistical analysis was based on three replicates computed on the statistica package Origin 6.1 (Origin Lab Corporation, USA). Statistical significance was performed as Student's t-test. Mean values and standard deviations were calculated. Statistically significant results were expressed at $*-\mathrm{P}<0.05$; ** $\mathrm{P}<0.01 ; * * *-\mathrm{P}<0.001$

\section{RESULTS AND DISCUSSION}

\section{Antioxidant activity}

Plant-derived compounds are an enduring source of phytochemicals possessing a list of therapeutic implementations.

In the molecular pathogenesis of plants', animals', and humans' disorders, oxidative stress contributed with free radicals overproduction is suspected to play significant role. Therefore, the screening for the free radicals scavenging regulators of natural and synthetic nature and studying their antiradical processes remain relevant.

All plant compounds concerning animal organisms have biological activity of an extremely wide spectrum, due to the diversity of their chemical structure, and are currently in the center of scientific attention. In connection with the foregoing, the search for antioxidants and the study of their inhibitory effect on the processes of free radical oxidation. In this regard, the effect of various concentrations of quercetin and dihydroquercetin on preventing $\mathrm{Fe}^{2+} /$ ascorbateinduced mitochondria lipid peroxidation was studied in vitro.

The introduction into the external medium the system, including $\mathrm{Fe}^{2+} /$ ascorbate activates lipid oxidation, that in turn destroys mitochondria membrane barrier function and leads to mitochondria swelling (Fig. 2). When quercetin and dihydroquercetin at a minimal dose of $2 \mu \mathrm{M}$ are added into external solution, containing $\mathrm{Fe}^{2+} /$ ascorbate, the antioxidant properties of polyphenols are observed that is reflected in mitochondria swelling inhibition. The effect of quercetin and dihydroquercetin on the process of mitochondrial membranes peroxidation revealed dose-dependent manner. Also, at the concentration of $10 \mu \mathrm{M}$ both compounds totally suppressed the mitochondria swelling proving the inhibition of lipid oxidation with $\mathrm{IC}_{50}$ values as follow $6.08 \pm 0.06 \mu \mathrm{M}$ (quercetin) and $\mathrm{IC}_{50}=8.1 \pm 0.09 \mu \mathrm{M} \quad$ (dihydroquercetin)

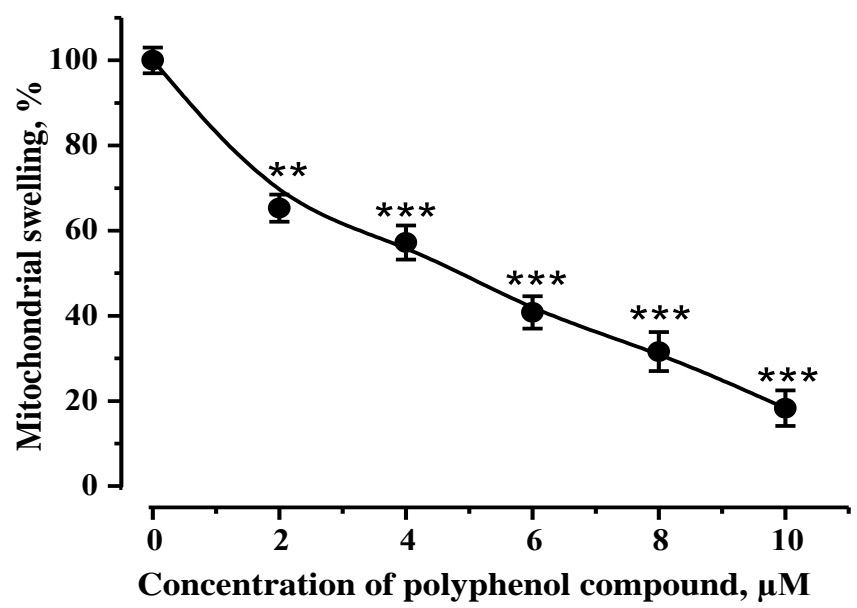

A 


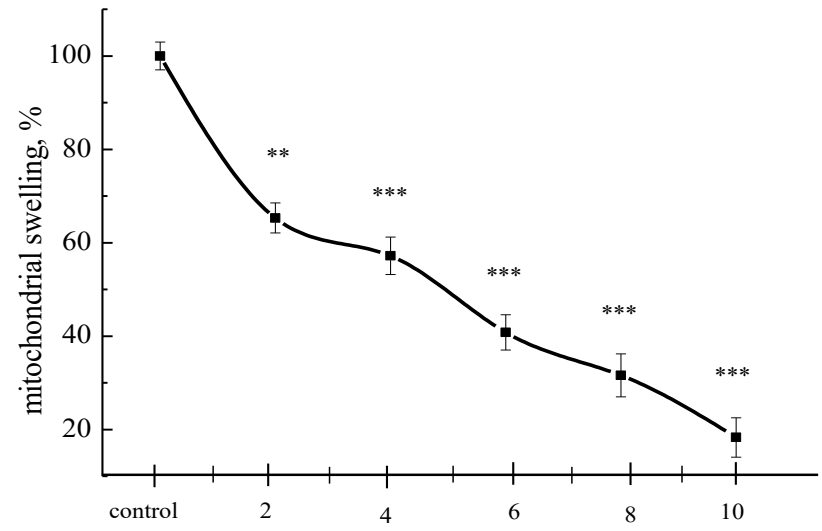

Concentration of polyphenol compound, micromole

Figure 2 Influence of quercetin (A) and dihydroquercetin (B) on the $\mathrm{Fe}^{2+} /$ ascorbate generated mitochondria swelling. External medium was as follow: $\mathrm{KCl}(125 \mathrm{mM})$, Tris-HCl $(10 \mathrm{mM}), \mathrm{pH} 7.4 ; \mathrm{FeSO}_{4}(10 \mu \mathrm{M})$, ascorbate $(600 \mu \mathrm{M})$ protein content $0.5 \mathrm{mg} / \mathrm{ml}$

Thus, obtained experiments show that quercetin has higher AOA compared to its derivative dihydroqercetine. The antioxidant properties of polyphenolic compounds are strongly up to the number of hydroxyl groups in the benzene ring, their position, degree of shielding, and also on the nature of other substituents that affect the electron density of the benzene ring (Yashin, 2014). The literature also provides data that the arrangement of hydroxyl groups in the benzene ring has a greater role in the manifestation of AOA than their number (Amič, 2003) The presence of several hydroxyl groups in the core, especially in the ortho- and para-positions to each other, causes special sensitivity to the action of oxidants. These phenols are extremely easy to oxidize and are good reducing agents. For example, ortho position substituted with hydroxyl groups undergo intramolecula repulsion, so their AOA increases compared to isomers in which the OH-groups occupy meta position. Probably, the higher AOA of quercetine depends on electron density of the benzene ring.

\section{Conductivity}

It is known that alkaline earth metal cations are capable, under certain conditions, of forming coordination bonds with oxygen-containing molecules. To obtain more direct experimental evidence on the complexing (chelating) properties of the studied polyphenols with cations of iron, the method of conductometry was used. As iron-binding property of polyphenols has been also proposed as their mechanism of cell protection against oxidative stress, the equilibrium constant between polyphenol and iron ions may provide insight into the mechanism of antioxidant effect.

The study of the electrical conductivity of divalent metal salts $\left(\mathrm{Fe}^{2+}\right)$ in an aqueous solution in the presence of studied polyphenols did not confirm the assumption that these compounds are capable of forming coordination type compounds. An analysis of experimental data shows that with an increase in the concentration of the studied polyphenol compound, as well as an increase in the concentration of divalent metal ions, the electrical conductivity of the solution containing $\mathrm{Fe}^{2+}$ cations does not change and does not reach a plateau (Fig. 3). However, presence EDTA in solution the electrical conductivity changes and reach plateau which indicates about chelating of metal ions with EDTA.

An analysis of experimental data shows that an increase in the concentration of polyphenols and divalent metal ions in a solution does not change the electrical conductivity.

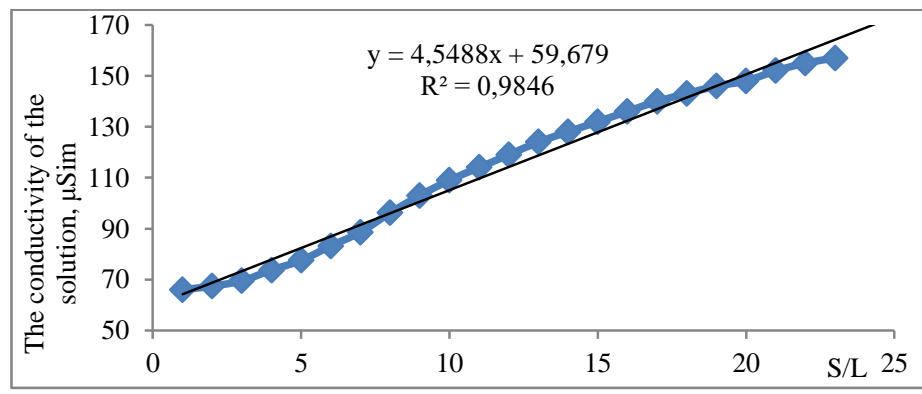

Figure 3 Typical conductometric titration curve of quercetin and dihydroquercetin with a $\mathrm{Fe}^{2+}$ solution (where $\mathrm{S}$ is the salt concentration, $\mathrm{L}$ is the polyphenol concentration, $\mu \mathrm{M}$ ).
Thus, it can be concluded that AOA of polyphenols is not associated with the chelation of divalent cations by the studied polyphenols.

\section{Antiradical activity}

Determination of mitochondrial swelling induced by the $\mathrm{Fe}^{2+} /$ ascorbate system is one classic method for studying the antioxidant properties of biologically active compounds

In the literature, AOA of polyphenol compounds is associated both with their ability to chelate various metal ions (Tripathi, Rastogi, 1981), and directly interact with reactive oxygen species: OH radicals (Takahama, 1984), O2 (Takahama, 1985), and singlet oxygen (Youngman, Takahama et.al, 1984). Besides, polyphenols can interact and/or bind the components of the reaction medium (Riedl, Carando et.al, 2002), which can lead to distortion of the results. The use of the $\mathrm{Fe}^{2+} /$ ascorbate-induced system does not directly assess the contribution of every single effect to the total antioxidant activity of the polyphenols.

Thus screening of compounds, that having free valence electrons are still stable organic radicals, seems reasonable (Gayibov, Komilovi, et al., 2017). For example, ortho-substituted diphenols have four electrons that can reduce various radicals (Pochinok, Tarakhovsky, et al., 1985). In this regard, the antiradical activity of polyphenols can be directly associated with their AOA.

In this regard, the antiradical activity of quercetin and dihydroquercetin against DPPH free radical was studied. To do this, we used a technique based on antioxidants' ability to reduce the molecules of 2,2-diphenyl-1-picrylhydrazyl (DPPH) (Gayibov et al., 2012). We studied the kinetics of drug recombination with the stable radical DPPH. When the studied compounds are added to the alcohol solution of DPPH, the color of the solution changes, which corresponds to the transition of DPPH to a nonradical form. In fig. 4 (experimental points) presents the kinetics of changes in the DPPH optical density with the addition of the studied compounds.
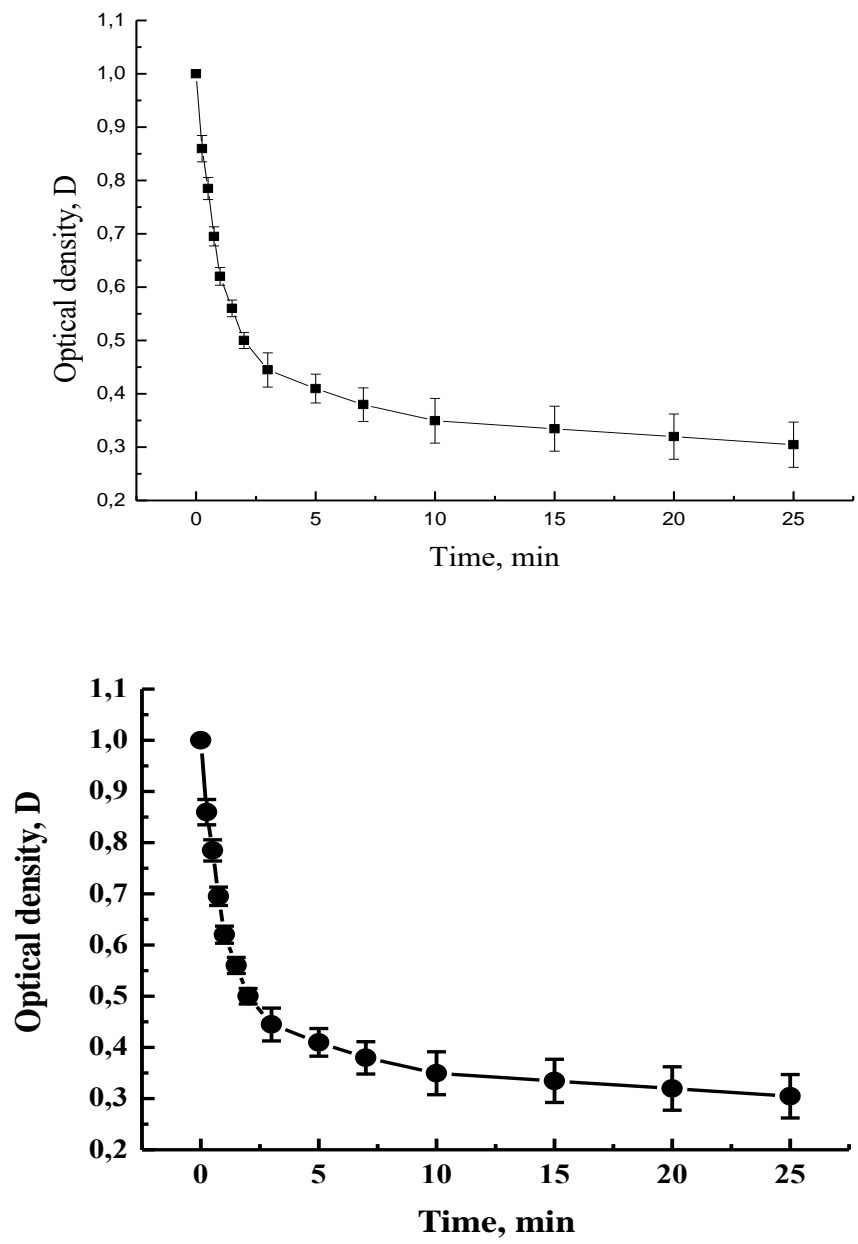

Figure 4 Kinetic curves of ARA of quercetin in ethanol solutions of DPPH. The concentration of polyphenol is 10 micromole.

To compare the ARA of the studied polyphenols, we selected a concentration of $50 \mu \mathrm{l}$ for each compound from the prepared alcohol solution of the substance at a concentration of $10^{-3} \mathrm{M}$. Analyzing the results, we can conclude that the optical density of the ethanol solution of DPPH decreases which indicates their antiradical ability. 
From experimental data, it follows that the studied compounds have a high ability to quench free radicals. To quantify the antiradical activity, we used the parameter $t_{50}$ - the time required for the studied drugs to decrease the initial concentration of the radical to $50 \%$, chemical reaction constant $(\mathrm{k})$ and half inhibition concentration $\left(\mathrm{IC}_{50}\right)$

\begin{tabular}{llllll}
$\boldsymbol{K} \mathbf{1 0}^{-\mathbf{3}}, \mathbf{c}^{-\mathbf{1}}$ & & $\mathrm{IC}_{50}, \mathrm{mcl}$ & $\mathrm{t}_{50, \mathrm{sec}}$ \\
\hline $\mathrm{DQ}$ & $\mathrm{Q}$ & $\mathrm{DQ}$ & $\mathrm{Q}$ & $\mathrm{DQ}$ & $\mathrm{Q}$ \\
1,2 & 5,3 & 14,3 & 7,2 & 105 & 9,6 \\
\hline
\end{tabular}

Thus, the studied compounds are characterized by a strong ability of components to react with free radicals

The correlation coefficient between ARA and AOA of polyphenol compounds is $\mathbf{r}=\mathbf{0 . 8 9}$.

Our main interest in the investigation of AOA/ARA activity was to clarify the mechanism of AOA of two studied polyphenols depending on their chemical structure. It is well known that the antiradical/antioxidant of polyphenolic compounds is up to the number and location of hydroxyl groups in the benzene ring of polyphenols (Yashin, 2014). In the molecules of quercetin and dihydroquercetin there is the same number of hydroxyl groups. However, the antiradical activity of dihydroquercetin is significantly lower than the ARA of quercetin. Higher ARA of quercetin, might possibly due to the numerous existence of double bonds in comparison to the molecule of dihydroquercetin Thus, we can assume that the high AOA/ARA of quercetin compared with its derivative is associated with the most energetically favorable state due to the distribution of electron density in the benzene ring.

When the quercetin donates an electron to free radical, initiating quercetin radical formation, due to resonance this newly formed radical lacks sufficient energy to approach reactive nature (Mariani et al., 2008). The structural groups that stabilize quercetin and specify its antioxidant features are considered to be the 3- and 5-hydroxyl groups together with 4-oxo group and B ring $o$-dihydroxyl groups (Hollman and Katan, 1997). This electron donating groups transfer electrons to the functional rings thus increasing the amount of resonance forms (Mariani et al., 2008).

On the base of the conductometric titration, we considered that there are no complexes of polyphenols with $\mathrm{Fe}^{2+}$ ions which could decrease the LPO process in the membrane due to chelate of metal ions by polyphenols. It is reasonable to suppose that AOA of polyphenols related to the non-polar part of quercetin and dihydroquercetin molecules extend into the acyl chain region of mitochondrial membrane and quench free radicals.

\section{Inhibition of mPTP}

Mitochondrial permeability transition pore (mPTP) approved to manifest the key role in the functional parameters of the cell. Thus, mPTP plays crucial part as trigger of apoptosis and necrosis under oxidative stress, ischemia/reperfusion as well as $\mathrm{Ca}^{2+}$ toxicity in liver cells (Kim et al., 2013). In this case the mechanism of cardioprotection of the most cardiovascular drugs is based on direct mPTP inhibition, as well as decreasing level of mPTP opening triggers, calcium overload and/or scavenging reactive oxygen species. According to the Akopova's data (Akopova, Kolchinskaya et al., 2011), mPTP goes into the open state as a result of the $\mathrm{Ca}^{2+}$ overload, induction of lipid peroxidation, the formation of ROS and closes in the presence of antioxidants or cation chelators (Asrarov, Komilov, et al., 2015).

Since $\mathrm{Ca}^{2+}$-dependent $\mathrm{mPTP}$ is a key factor in ensuring the permeability of mitochondrial membranes (Akopova, Nosar et al., 2013), in the following experiments the effect of quercetin and its derivative dihydroquercetin on $\mathrm{mPTP}$ activity (Fig. 5) was investigated. The introduction of $10 \mu \mathrm{M} \mathrm{Ca}^{2+}$ ions into the external solution induces mitochondrial swelling (Fig. 5, cont.), which indicates that $\mathrm{mPTP}$ is in the open state. Cyclosporin A (CsA), a specific mPTP blocker, avoids mitochondria from being swollen under the above-mentioned conditions (Fig. 5, A), i.e. mPTP remains in closed state even when $\mathrm{Ca}^{2+}$ ions are in medium.

According to experimental data, in $\mathrm{Ca}^{2+}$ containing medium, quercetin at $50 \mu \mathrm{M}$ inhibits opening of mPTP up to $18.6 \%$, at $200 \mu \mathrm{M}$ inhibits opening of mPTP up to $89.7 \%$ in comparison to control experiment. The data suggests that quercetin, depending on the concentration, inhibits the opening of rat liver mPTP. This is probably due to the antioxidant properties of quercetin (Gayibov, Komilov et al. 2017), that is universal mechanism of stabilizing membranes. Our further investigations were devoted to studying the influence of dihydroquercetin on mPTP activity on the mitochondrial membrane. We were interested in the comparison interaction of quercetin and its derivative dihydroquercetin with mPTP. The concentration of dihydroquercetin was the same $(10-100 \mu \mathrm{M})$.

From the data in fig. 5 (B) inhibition of mPTP opening by dihydroquercetin is not much different from quercetin activity.

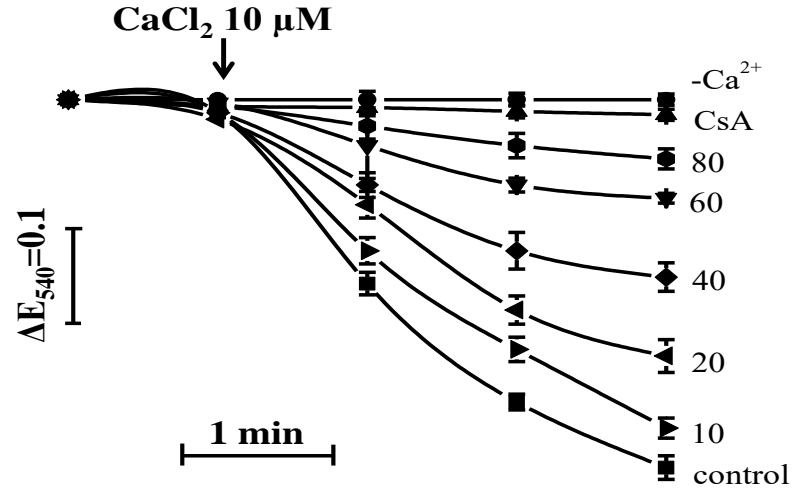

Concentration of compound, $\mu \mathrm{M}$

A

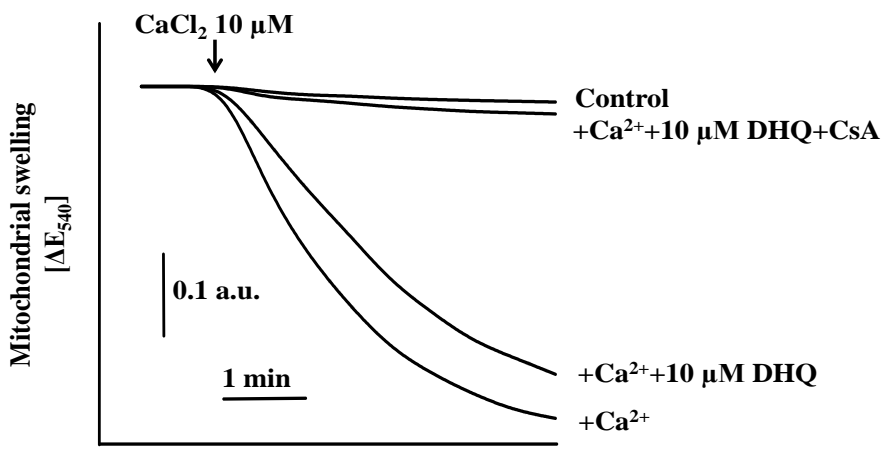

Figure 5 Influence of quercetin (A) and dihydroquercetin (B) on cyclosporineinduced mitochondria swelling. External medium was as follow: sucrose (200 $\mathrm{mM})$, EGTA $(20 \mu \mathrm{M})$, succinate $(5 \mathrm{mM})$, rotenone $(2 \mu \mathrm{M})$, oligomycin $(1$ $\mu \mathrm{g} / \mathrm{ml})$, Tris $(20 \mathrm{mM})$, HEPES $(20 \mathrm{mM}), \mathrm{KH}_{2} \mathrm{PO}_{4}(1 \mathrm{mM})$, pH adjusted to 7.2 , protein content $0,3-0,4 \mathrm{mg} / \mathrm{ml} ;(\mathrm{n}=3-5)$.

mPTP opening leads to mitochondrial dysfunction through ATP hydrolysis and oxidative phosphorylation uncoupling, ultimately resulting in cell death. The opening state of mPTP has been examined explored broadly in pathology of cardiovascular disorders such as ischemia/reperfusion and heart failure. Hence, mPTP is recognized as a therapeutic target for pharmacological and nonpharmacological strategies by blocking pore activation over direct blockage of mPTP components and/or indirect mechanism of blockage of mPTP inducers (Javadov et al., 2009). The list of indirect mechanisms of mPTP blockade includes $\Delta \Psi \mathrm{m}$ modulation, redox state, mitochondrial mass regulation, calcium retention capacity and fusion/fission processes. Closer approach reveals alterations in protein expression, post-translational modifications and interactome disturbance, thus affecting signaling pathways.

\section{mitoKATP activation}

Potassium ions are the main ionic component of not only the cytoplasm but also the mitochondrial matrix. The direction of the electric field on the inner membrane of mitochondria favors the transport of potassium ions from the cytoplasm to the matrix. Thus, the presence of any $\mathrm{K}^{+}$-selective channels, including the mitoKATP channel, in the inner mitochondrial membrane will be accompanied by changes in the mitochondrial volume and regulation of the state of the $\mathrm{Ca}^{2+}$-dependent mPTP. Modulation of the conductivity of the mitoKATP channel underlies changes in mitochondrial functions under different pathologic conditions, however, the physiological role of this phenomenon is not entirely clear (Akopova, Kolchinskaya et.al, 2011). Fig. 6 shows experimental data using quercetin as mitoKATP channel activator. The data shows that quercetin, starting from a concentration of 10 and $20 \mu \mathrm{M}$, stimulates the mitoKATP channe opening (Fig. 6), and at concentrations of $80 \mu \mathrm{M}$ or more, an exit to the board is observed. Regarding the action of quercetin on the activity of the mitoKATP channel, the experimental line observed is saturation curve line representing dose-dependent effect. 

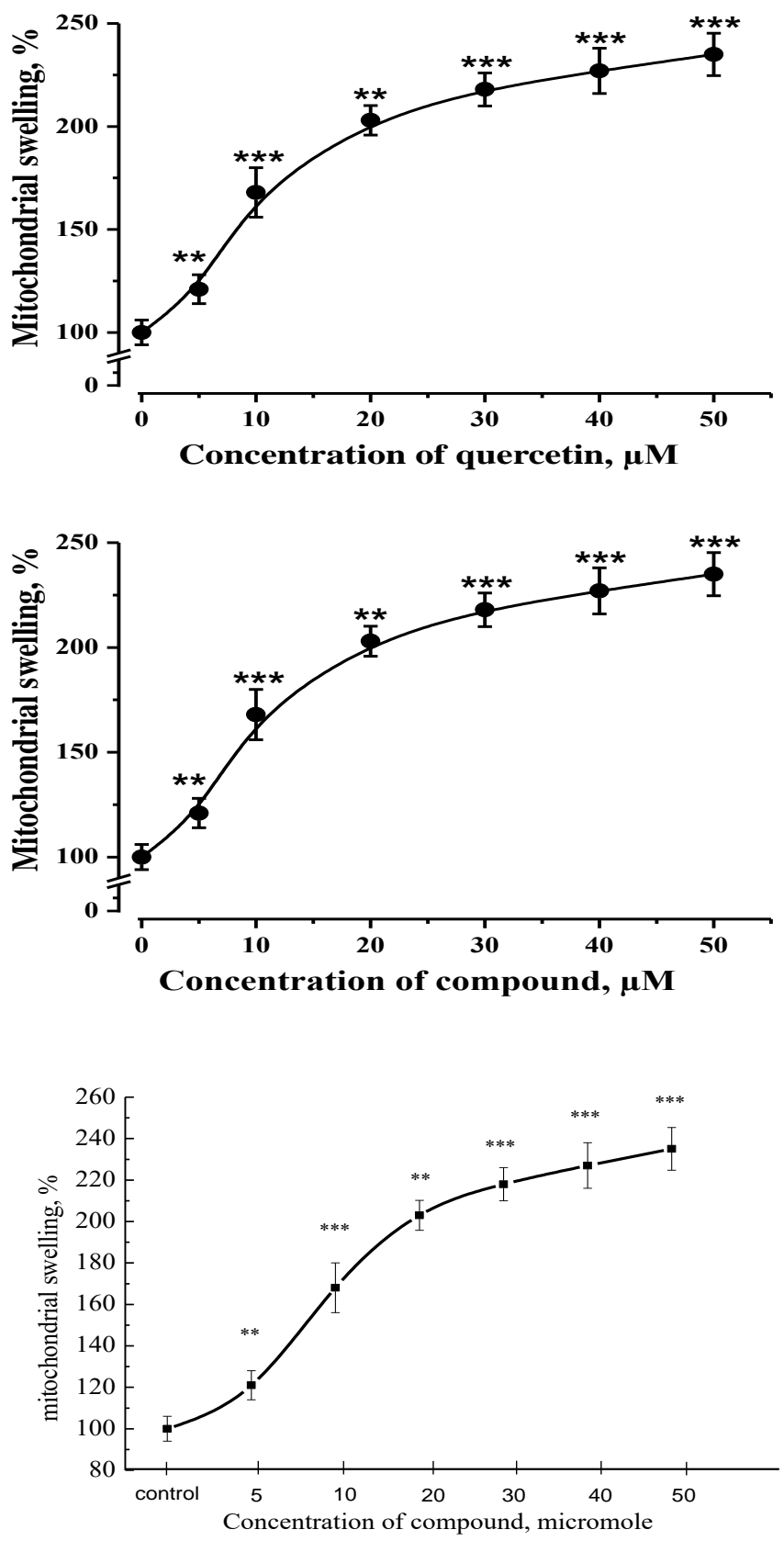

A

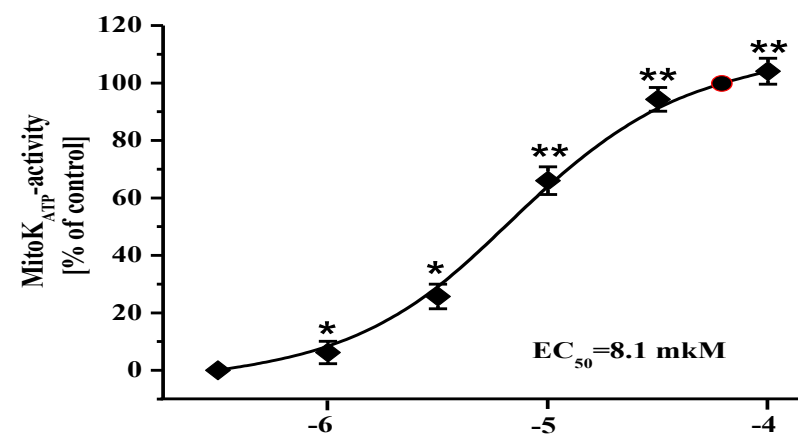

B

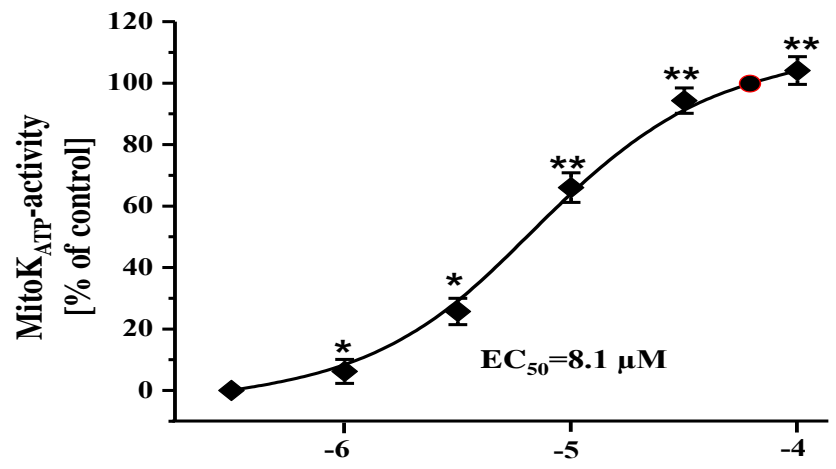

Dihydroquercetin, $\lg [\mu \mathrm{M}]$

Figure 6 Influence of quercetin (A) and dihydroquercetin (B) on the mitoKATP channel activation. External medium was as follow (mM): $\mathrm{KCl}(125)$, Hepes (10), succinate (5), $\mathrm{MgCl}_{2}(1), \mathrm{K}_{2} \mathrm{HPO}_{4}\left(2.50, \mathrm{KH}_{2} \mathrm{PO}_{4}(2.5)\right.$, rotenone $(0.005)$ and oligomycin (0.001), pH 7,4. (** - $\mathrm{P}<0,01, * * *$ - $\mathrm{P}<0,001 ; \mathrm{n}=4)$

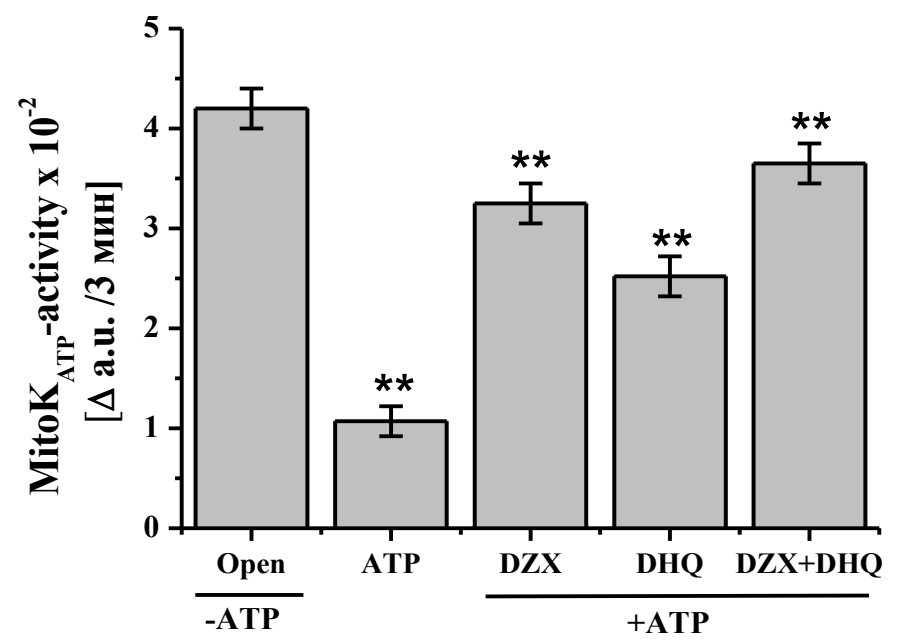

Figure 7 The effect of dihydroquercetin on the state of the mitoKATP channel of rat liver $(* * \mathrm{P}<0.01 ; \mathrm{n}=3)$.

Open: open conformation, control without ATP (activity of the mito-CATF channel)

ATP: MitocATF channel state in the presence of $200 \mu \mathrm{M}$ ATP

DZX: mitoKATP channel activity in the presence of $30 \mu \mathrm{M}$ diazoxide $+200 \mu \mathrm{M}$ ATP

DHQ: MitocATF channel activity with $80 \mu \mathrm{M} \mathrm{DHQ}+200 \mu \mathrm{M}$ ATP

DZX + DHQ: mitoCATP channel activity with $30 \mu \mathrm{M}$ diazoxide $+80 \mu \mathrm{M}$ DHQ $+200 \mu \mathrm{M}$ ATP.

The dual role of reactive oxygen species was widely accepted. On one hand in high concentrations ROS can damages cells; on the other hand they display messenger's activity in cellular signaling thus inducing cells survival in stress conditions. Interestingly ROS also can stimulate mitoKATP activation under oxidation stress in the heart and brain, conferring the cells protective effect (Badziuk et al., 1999). The functioning of mitoKATP depends on the redox state of the active groups of the channel protein. It has been found that redox agents modulate the work of mitoKATP. For example, the electron donor ndimethylaminoethyl benzoate activates mitoKATP, and the electron acceptors pelargonidine inhibits the channel (Grigoriev $\boldsymbol{e t}$ al, 1999), which is probably due to their effect on the SH groups of the channel. Perhaps the activation of this channel by quercetin and dihydroquercetin is related to the fact that they are electron donors (antioxidants).

\section{CONCLUSION}

It is known that polyphenolic compounds exhibit antioxidant, anti-inflammatory, immunomodulatory and many other actions, which creates the prerequisites for creating drugs based on them. In this case polyphenols are advantageous compounds due to their low toxicity and sufficient aqueous solubility.

Summarizing above mentioned data of polyphenol compounds activity on the mitochondrial level we can conclude that compounds are determined to some 
extent by the influence on the mitochondrial membranes structure, free radical oxidation and oxidative phosphorylation processes.

As it was shown earlier by M.I. Asrarov et al. (Asrarov, Komilov, et al., 2015), a trend to improve some functional characteristics of mitochondria by the polyphenolic compounds provides the background to assume possible antihypoxic, cardio protective and antihyperglicemic effects of quercetin and dihydroquercetin. Further studies are required to validate the role of quercetin and dihydroquercetin as antihypoxic, cardio protective and antihyperglicemic agent on organismal level.

\section{REFERENCES}

Akao, M., Ohler, A., O'Rourke, B., \& Marbán, E. (2001). Mitochondrial ATPsensitive potassium channels inhibit apoptosis induced by oxidative stress in cardiac cells. Circulation research, 88(12), 1267-1275. https://doi.org/10.1161/hh1201.092094

Akopova, O. V., Nosar', V. I., Man'kovskaia, I. N., \& Sagach, V. F. (2013). Ukrains'kyi biokhimichnyi zhurnal (1999 ), 85(5), 37-49. https://doi.org/10.15407/ubj85.05.037

Akopova, O. V., Nosar', V. I., Man'kovskaia, I. N., \& Sagach, V. F. (2013). Ukrains'kyi biokhimichnyi zhurnal (1999) ), 85(5), 37-49. https://doi.org/10.15407/ubj85.05.037

Andreev I.M., Malenkov G.G., Shkrob A.M., Shemyakin M.M. (1971) Conductometric study of complexes of cyclic depsipeptides and peptides with alkali metal ions. Molecules. biol. 5(4): 614-623. (in Russian language)

Asrarov M.I., Komilov E.J., Ergashev N.A., Pozilov M.K., Eshbakova K.A., Toshmatov Z.A., Tashbekova M.Kh. (2015) To the mechanism of action of luteolin flavone on the function of rat liver mitochondria. Biological, medical and pharmacological chemistry questions, 12: 38-43. (in Russian language)

Badziuk, O. B., Mazur, I., \& Kosterin, S. O. (2011). Ukrains'kyi biokhimichnyi zhurnal (1999), 83(3), 48-57.

Bouktaib M., Atmani A., Rolando C. (2002) Regio- and stereoselective synthesis of the major metabolite of quercetin, quercetin-3-O-b-Dglucuronide. Tetrahedron Letters 43: 6263-6266. https://doi.org/10.1016/S0040-4039(02)01264-9

Brewer M.S. (2011) Natural antioxidants: sources, compounds, mechanisms of action, and potential applications. Comp. rev. food science \& food safety. 10(4) 221-247. https://doi.org/10.1111/j.1541-4337.2011.00156.x.

Cercile Martel, Le Ha Huynh, Anne Garnier, Renere Ventura-Clapier, and Catherine Brenner. (2012) Inhibition of the mitochondrial permeability transition for cytoprotection: direct versus indirect mechanisms. Hindawi Publishing Corporation Biochemistry Research International. 2012: 13 https://doi.org/10.1155/2012/213403

Mariani, C., Braca, A., Vitalini, S., De Tommasi, N., Visioli, F., \& Fico, G. (2008). Flavonoid characterization and in vitro antioxidant activity of Aconitum anthora L. (Ranunculaceae). Phytochemistry, 69(5), 1220-1226. https://doi.org/10.1016/j.phytochem.2007.12.009

Chesnokova N.P., Morrison V.V., Ponukalina E.V., Afanasyeva G.A., Bizenkova M.N., Barsukov V.Yu., Morozova O.L. , Polutova N.V., Zhevak T.N. (2009) On the role of activation of free radical oxidation in the structural and functiona disorganization of biosystems under pathological conditions. Basic research. 5 122-130. (in Russian language)

Council for International Organizations... - (Internet) in 2012. Internationa guiding principles for biomedical research involving animals. (Cited 5 Augus 2014). Available at: http://www.cioms.ch/images/stories/CIOMS/IGP2012.pdf.

Danilenko L.M. (2015) The role of mitochondrial atp-dependent potassium channels in the cardioprotective effect nicorandila on the model koronarolitikov myocardial infarction. Research result Series "Medicine and pharmacy" 4(6) 40-44 https://doi.org/10.18413/2313-8955-2015-1-4-40-44 (in Russian language) Dave Z., Byfield M., Bossy-Wetzel E. (2008). Assessing mitochondrial outer membrane permeabilization during apoptosis. Methods, 46(4): 319-23. https://doi.org/10.1016/j.ymeth.2008.10.019.

Facundo, H. T., de Paula, J. G., \& Kowaltowski, A. J. (2007). Mitochondrial ATP-sensitive $\mathrm{K}+$ channels are redox-sensitive pathways that control reactive oxygen species production. Free radical biology \& medicine, 42(7), 1039-1048. https://doi.org/10.1016/j.freeradbiomed.2007.01.001.

Ferranti, R., da Silva, M. M., \& Kowaltowski, A. J. (2003). Mitochondrial ATP sensitive $\mathrm{K}+$ channel opening decreases reactive oxygen species generation. FEBS letters, 536(1-3), 51-55. https://doi.org/10.1016/s0014 5793(03)00007-3

Fornazari, M., de Paula, J. G., Castilho, R. F., \& Kowaltowski, A. J. (2008) Redox properties of the adenoside triphosphate-sensitive $\mathrm{K}+$ channel in brain mitochondria. Journal of neuroscience research,86(7), 1548-1556. https://doi.org/10.1002/jnr.21614

García-Mediavilla V., Crespo I., Collado P.S., Esteller A., Sánchez-Campos S., Tuñón M.J., González-Gallego J. (2007). The anti-inflammatory flavones quercetin and kaempferol cause inhibition of inducible nitric oxide synthase, cyclooxygenase- 2 and reactive $\mathrm{C}$-protein, and down-regulation of the nuclear factor kappaB pathway in Chang Liver cells. Eur. J. Pharmacol. 557(2-3):221-229 https://doi.org/10.1016/j.ejphar.2006.11.014
Garlid, K. D., \& Halestrap, A. P. (2012). The mitochondrial K(ATP) channel-fact or fiction?. Journal of molecular and cellular cardiology, 52(3), 578-583. https://doi.org/10.1016/j.yjmcc.2011.12.011

Gayibov U.G., Kamaev F.G., Aripov T.F. (2012) NMR study of the interaction of gossypol with DPPH in various solvents. Reports of the Academy of Sciences of the Republic of Uzbekistan. 3: 49-53. (in Russian language)

Gayibov U.G., Komilov E.J., Ergashev N.A., Rakhimov R.N., Abdullazhanova N.G., Asrarov M.I., Aripov T.F. (2017) The effect of PC-1 polyphenolic compound on the permeability of rat liver mitochondria. Reports of the Academy of Sciences of the Republic of Uzbekistan, 5: 49-53 (in Russian language)

Gayibov U.G., Komilov E.J., Ergashev N.A., Rakhimov R.N., Abdullazhanova N.G., Asrarov M.I., Aripov T.F. (2017) Antioxidant and membrane-active properties of PC-1. Uzbek biological journal. 2: 19-23. (in Russian language) Gayibov, U.G., Komilov, E.J., Rakhimov, R.N., Ergashev, N.A., Abdullajanova, N.G., Asrorov, M.I., Aripov, T.F. (2019) Influence of new polyphenol compound from euphorbia plant on mitochondrial function. J. Microbiol. Biotech. Food Sci, 8(4), 1021-1025. https://doi.org/10.15414/jmbfs.2019.8.4.1021-1025

Gayibov, U.G., Komilov, E.J., Rakhimov, R.N., Ergashev, N.A., Abdullajanova, N.G., Asrorov, M.I., Aripov, T.F. (2018) Antioxidant and Membrane-Active Properties of 1,4,6 tri-o-galloyl-2,3-valoneyl- $\beta$-d-glucose. European Journal of Medicine. Series $B, 5(1)$ : 3-15. (In the Russian language) https://doi.org/10.13187/ejm.s.b.2018.1.3

Gayibova, S., Ivanišová, E., Árvay, J., Hístková, M., Slávik, M., Petrová, J., Hleba, L., Tóth, T., Kacaniova, M., Aripov, T. (2019). In Vitro Screening of Antioxidant and Antimicrobial Activities of Medicinal Plants Growing in Slovakia. Journal of microbiology, biotechnology and food sciences, 8(6): 1281 1289. https://doi.org/10.15414/jmbfs.2019.8.6.1281-1289

Grigoriev, S. M., Skarga, Y. Y., Mironova, G. D., \& Marinov, B. S. (1999) Regulation of mitochondrial KATP channel by redox agents. Biochimica et biophysica acta, 1410(1), 91-96. https://doi.org/10.1016/s0005-2728(98)001790.

He, L., \& Lemasters, J. J. (2003). Heat shock suppresses the permeability transition in rat liver mitochondria. The Journal of biological chemistry, 278(19), 16755-16760. https://doi.org/10.1074/jbc.M300153200

Hollman, P. C., \& Katan, M. B. (1997). Absorption, metabolism and health effects of dietary flavonoids in man. Biomedicine \& pharmacotherapy = Biomedecine \& pharmacotherapie, 51(8),

305-310.

https://doi.org/10.1016/s0753-3322(97)88045-6.

Hund, T. J., \& Mohler, P. J. (2011). Differential roles for SUR subunits in KATP channel membrane targeting and regulation. American journal of physiology. Heart and circulatory physiology, 300(1),

$\mathrm{H} 33-\mathrm{H} 35$.

https://doi.org/10.1152/ajpheart.01088.2010

Jovanovic, S. V., Steenken, S., Boone, C. W., Simic, M. G. (1999). H-atom transfer is a preferred antioxidant mechanism of curcumin. J. Am. Chem Soc. 121:9677-9681 https://doi.org/10.1021/ja991446m

Karbarz M, Malyszko J (2008) Voltammetric behavior of Trolox in methanol and ethanol solutions. Electroanalysis. 20(17):1884-1890 https://doi.org/10.1002/elan.200804263

Kim, J., Kim, J. A., McGinty, R. K., Nguyen, U. T., Muir, T. W., Allis, C. D., \& Roeder, R. G. (2013). The n-SET domain of Set1 regulates H2B ubiquitylationdependent H3K4 methylation. Molecular cell,49(6), 1121-1133. https://doi.org/10.1016/j.molcel.2013.01.034

Labinskyy, N., Csiszar, A., Veress, G., Stef, G., Pacher, P., Oroszi, G., Wu, J., \& Ungvari, Z. (2006). Vascular dysfunction in aging: potential effects of resveratrol, an anti-inflammatory phytoestrogen. Current medicinal chemistry, 13(9), 989-996. https://doi.org/10.2174/092986706776360987

Lobo, V., Patil, A., Phatak, A., \& Chandra, N. (2010). Free radicals, antioxidants and functional foods: Impact on human health. Pharmacognosy reviews, 4(8), 118-126. https://doi.org/10.4103/0973-7847.70902.

Zhang, M., Swarts, S. G., Yin, L., Liu, C., Tian, Y., Cao, Y., Swarts, M., Yang, S., Zhang, S. B., Zhang, K., Ju, S., Olek, D. J., Jr, Schwartz, L., Keng, P. C. Howell, R., Zhang, L., \& Okunieff, P. (2011). Antioxidant properties of quercetin. Advances in experimental medicine and biology, 701, 283-289. https://doi.org/10.1007/978-1-4419-7756-4_38

Meng, L. M., Ma, H. J., Guo, H., Kong, Q. Q., \& Zhang, Y. (2016). The cardioprotective effect of naringenin against ischemia-reperfusion injury through activation of ATP-sensitive potassium channel in rat. Canadian journal of physiology and pharmacology, 94(9), 973-978. https://doi.org/10.1139/cjpp2016-0008

Mullen, W., Rouanet, J. M., Auger, C., Teissèdre, P. L., Caldwell, S. T., Hartley, R. C., Lean, M. E., Edwards, C. A., \& Crozier, A. (2008). Bioavailability of [2 (14)C]quercetin-4'-glucoside in rats. Journal of agricultural and food chemistry, 56(24), 12127-12137. https://doi.org/10.1021/jf802754s.

Shankar, S., Singh, G., \& Srivastava, R. K. (2007). Chemoprevention by resveratrol: molecular mechanisms and therapeutic potential. Frontiers in bioscience : a journal and virtual library, 12, 4839-4854. https://doi.org/10.2741/2432

Murota, K., \& Terao, J. (2003). Antioxidative flavonoid quercetin: implication of its intestinal absorption and metabolism. Archives of biochemistry and biophysics, 417(1), 12-17. https://doi.org/10.1016/s0003-9861(03)00284-4. 
Mylonas, C., \& Kouretas, D. (1999). Lipid peroxidation and tissue damage. In vivo (Athens, Greece), 13(3), 295-309.

Nadeev A.D., Goncharov N.V. (2014) Active forms of oxygen in the cells of the cardiovascular system. Complex problems of cardiovascular diseases. 4: 80-94. https://doi.org/10.17802 / 2306-1278-2014-4-80-94 (in Russian language)

Novikov, V. E., \& Levchenkova, O. S. (2013). Eksperimental'naia i klinicheskaia farmakologiia, 76(5), 37-47. (in Russian language)

Peterson G. L. (1977). A simplification of the protein assay method of Lowry et al. which is more generally applicable. Analytical biochemistry, 83(2), 346-356. https://doi.org/10.1016/0003-2697(77)90043-4.

Pochinok T.V., Tarakhovsky M.L., Portnyagina V.A., Denisova M.F., Vonsyatsky V.A., Aleksandrov A.N., Melnichuk V.A. , (1985) Express method for determining the antiradical activity of drugs. Chem. Farm. Journal 5: 565 567. (in Russian language)

Pozhilova E.V., Levchenkova O.S., Novikov V.E. (2012) The regulatory role of the mitochondrial pore and the possibility of its pharmacological modulation. Reviews on wedge. farm. and medicine. therapy. 12: 13-19. (in Russian language) Riedl K.M., Carando S., Alessio H.M., CarthyM.Mc, (2002) Antioxidant activity of tannins and tannin-protein complexes: assessment in vitro and in vivo. Free radicals in Food., 807: 188-200

Rustamova R.P., Irgasheva G.M., Khushbaktova Z.A., Klemesheva L.S., Shirinova I.A., Almatov K.T. (2005) The effect of certain flavones on the energy metabolism of mitochondria. Message 1. Q. biol., honey. and farm. Chem. 4: 3945. (in Russian language)

Javadov, S., Karmazyn, M., \& Escobales, N. (2009). Mitochondrial permeability transition pore opening as a promising therapeutic target in cardiac diseases. The Journal of pharmacology and experimental therapeutics, 330(3), 670-678. https://doi.org/10.1124/jpet.109.153213

Samavati, L., Monick, M. M., Sanlioglu, S., Buettner, G. R., Oberley, L. W., \& Hunninghake, G. W. (2002). Mitochondrial K(ATP) channel openers activate the ERK kinase by an oxidant-dependent mechanism. American journal of physiology. Cell physiology, 283(1), C273-C281. https://doi.org/10.1152/ajpcell.00514.2001.

Hogeboom, G. H., Schneider, W. C., \& Pallade, G. E. (1948). Cytochemica studies of mammalian tissues; isolation of intact mitochondria from rat liver; some biochemical properties of mitochondria and submicroscopic particulate material. The Journal of biological chemistry, 172(2), 619-635.

Solovyova, N. V., \& Kuznetsova, T. Y. (2015). Quantum chemical modeling of antioxidant activity of glutathione interacting with hydroxyl- and superoxide anion radicals. Ukrainian biochemical journal, 87(2), 156-162. https://doi.org/10.15407/ubj87.02.156.

Takahama U. (1984). Hydrogen peroxide-dependent oxidation of flavonols by intact spinach chloroplasts. Plant physiology, 74(4), 852-855. https://doi.org/10.1104/pp.74.4.852

Takahama U. (1985). O2- -dependent and -independent photooxidation of quercetin in the presence and absence of riboflavin and effects of ascorbate on the photooxidation. Photochemistry and photobiology,42(1), 89-91. https://doi.org/10.1111/j.1751-1097.1985.tb03551.x

Takahama U., Youngman R.J., Elstner E.F., (1984) Transformation of quercetin by singlet oxygen generated by a photosensitized reaction., 7: 175-181.

Takei M., Hiramatsu M., Mori A. (1994) Inhibitory effects of calcium antagonists on mitochondrial swelling induced by lipid peroxidation of arachidonic acid in the rat brain in vitro. Neurochemical research. 19(9): 1199-1206.

Teixeira S. (2002). Bioflavonoids: proanthocyanidins and quercetin and their potential roles in treating musculoskeletal conditions. The Journal of orthopaedic and sports physical therapy, 32(7), 357-363. https://doi.org/10.2519/jospt.2002.32.7.357

Tripathi V.D., Rastogi R.P., (1981) Flavonoids in biology and medicine. J. Sci Ind Res., 40: 116-24

Tsujimoto, Y., \& Shimizu, S. (2007). Role of the mitochondrial membrane permeability transition in cell death. Apoptosis : an international journal on programmed cell death, 12(5), 835-840. https://doi.org/10.1007/s10495-0060525-7

Tsybulsky A.V., Popov A.M., Artyukov A.A., Kostetsky E.Ya., Krivoshapko O.N., Mazeyka A.N., Kozlovskaya E.P. (2011) Comparative study of the therapeutic effect of luteolin, rosmarinic acid and echinochrome $\mathrm{A}$ in experimental stress-induced cardiopathology. Biomed. chemistry. 57 (3): 314325. (in Russian language)

Vadziuk, O. B., \& Kosterin, S. A. (2008). Ukrains'kyi biokhimichnyi zhurnal (1999), 80(5), 45-51. (in Russian language)

Vianello A, Casolo V, Petrussa E, Peresson C, Patui S, Bertolini A, Passamont S, Braidot E, Zancani M. (2012) The mitochondrial permeability transition pore (PTP) - an example of multiple molecular exaptations? Biochim Biophys Acta, 1817(11): 2072-86. https://doi.org/10.1016/j.bbabio.2012.06.620.

Vladimirov, 2002 - Vladimirov Yu.A. (2002). Violation of the barrier properties of the inner and outer membranes of mitochondria, necrosis and apoptosis. Biological membranes, 19 (5): 356-377. (in Russian language)

Yang, J. Y., Della-Fera, M. A., Rayalam, S., Ambati, S., Hartzell, D. L., Park, H. J., \& Baile, C. A. (2008). Enhanced inhibition of adipogenesis and induction of apoptosis in 3T3-L1 adipocytes with combinations of resveratrol and quercetin. Life sciences, 82(19-20),

$1032-1039$

Yashin A.Ya. (2014) Influence of the structure of polyphenol antioxidant molecules on the sensitivity of amperometric detection in HPLC and injectionflow systems. Sorption and chromatographic processes. V. 14. Vol. 5 pp. 869878 (in Russian language) 